\title{
Hyperhomocysteinemia as a risk factor for ischemic stroke: an Indian scenario
}

\author{
M. Modi, S. Prabhakar, S. Majumdar ${ }^{1}$, M. Khullar', V. Lal, C. P. Das \\ Departments of Neurology and ${ }^{1}$ Experimental Medicine, Postgraduate Institute of Medical Education and Research, Chandigarh, India
}

\begin{abstract}
Background: Hyperhomocysteinemia has been proposed as an important risk factor for ischemic stroke worldwide, but data available from the Indian subcontinent is scarce. Aim: To study homocysteine levels in patients with ischemic stroke and compare it with age- and sex-matched controls. Settings and Design: Case-control prospective study. Materials and Methods: Fifty-seven patients with ischemic stroke and 30 controls were recruited for the study. They were subdivided into two subgroups ( $<40$ years and $>40$ years of age) and plasma fasting total homocysteine (tHcy) levels were measured. Statistical analysis used: Student's ' $t$ ' test and chisquare test. Results: The tHcy were significantly high in patients with stroke, compared to controls $(9.91 \pm 2.25 \mathrm{vs}$ $8.00 \pm 2.74 \mu \mathrm{mol} / / ; P<0.001)$. Significantly high levels were seen in both male patients compared to controls $(10.24 \pm 2.34$ vs $8.45 \pm 2.72 \mu \mathrm{mol} / / ; P=0.01)$ and female patients compared to controls $(9.08 \pm 1.81$ vs $6.79 \pm 2.60 \mu \mathrm{mol} / \mathrm{l} ; P=0.04)$. The tHcy levels were significantly high in patients with hypertension compared to normotensive patients (10.96 vs $9.49 \mu \mathrm{mol} /$ $\mathrm{I} ; P=0.01)$ and smokers compared to nonsmokers (11.17 vs $9.33 \mu \mathrm{mol} / \mathrm{l} ; P=0.01)$. Conclusions: Hyperhomo-cysteinemia emerged as an important independent risk factor for ischemic stroke. A strong positive correlation was also observed between hypertension, smoking, and high-tHcy levels in the present study.
\end{abstract}

Key words: Case-control study; homocysteine; ischemic stroke.

Stroke is one of the foremost causes of morbidity and mortality throughout the world, posing a major socio-economic challenge in the occupational and neuro-rehabilitational programmes for 'stroke-survivors.' Numerous risk factors for stroke have been identified and modification of these factors is the crux of primary and secondary prevention. ${ }^{[1]}$ Despite recent advances, only two-third of all strokes can be attributed to known causal risk factors. ${ }^{[2]}$ Large clinical trials of LDL cholesterol-lowering therapy reported adverse events in up to $19 \%$ of patients, despite this powerful intervention. This observation has intensified the search for 'new nonlipid' risk factors for atherosclerotic vascular disease (ASVD). ${ }^{[3]}$ Recently, there has been much interest in homocysteine, a sulfur containing aminoacid as an important risk factor for vascular diseases including stroke, independent of the long-recognized factors like hyperlipidemia, hypertension, diabetes mellitus, and smoking, ${ }^{[4]}$ although its association was described many decades ago. ${ }^{[5]}$ During the last decade, numerous studies observed a strong positive correlation between hyperhomocysteinemia and ischemic stroke ${ }^{[6]-[11]}$ while others could not establish the same. ${ }^{[12],[13]}$ The present study was planned to explore an association between homocysteine levels in Indian patients with ischemic stroke in this part of the country in view of the limited data available, so that some practical recommendation for screening and treatment of this modifiable risk factor could be provided.

\section{Materials and methods}

A prospective case-control study was planned to study homocysteine levels in patients of ischemic stroke and compare it with age- and sex-matched controls [Figure 1]. The patients were selected from those attending the emergency services or the out-patient department of our institute. A total of 57 patients with stroke and 30 years of age and sex-matched controls from the general population were included in the present study. The patients of ischemic stroke with multiple established risk factors such as diabetes, hypertension, and smoking in combination were excluded in the present study. The controls were selected from amongst age- and sex-matched healthy volunteers, patients with unrelated complaints and their relatives after informed consent. The cases and controls were subdivided into the following groups according to age. 


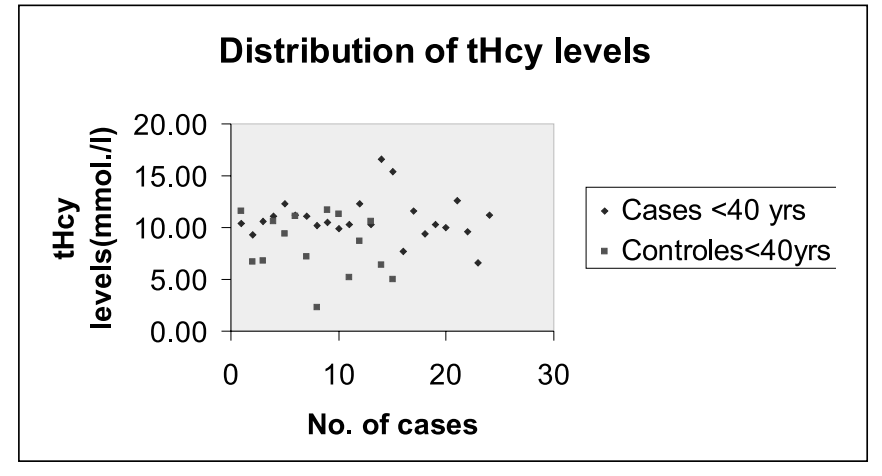

Figure 1: (A) Scattered diagram showing distribution of homocysteine levels in cases and controls $<40$ years of age ( $\mu \mathrm{mol} / \mathrm{l}$, micromoles per liter). (B) Scattered diagram showing distribution of homocysteine levels in cases and controls $>40$ years of age ( $\mu \mathrm{mol} / \mathrm{l}$, micromoles per liter)

Group I Patients with stroke $<40$ years of Group II Patients with stroke $>40$ years of age 24 subjects Group III Controls < $\quad 40$ years of age 15 subjects Group IV Controls > $\quad 40$ years of age 15 subjects

Ischemic stroke was defined as a stroke with either a normal CT brain scan or with an evidence of a recent infarct in the clinically relevant area of the brain on a CT or MRI brain scan performed within 3 weeks of the event. On the basis of clinical evaluation imaging and other investigations, only cases belonging to large artery disease and small artery disease were included in the present study, as per the predefined criteria. ${ }^{[9]}$ All patients with recent ( $\leq 3$ months) major systemic illness, including myocardial infarction, hepatic disease, renal disease, thyroid disease, cardiomyopathy, pregnancy, patients on drugs causing rise in homocysteine levels such as anticonvulsant medication, evidence of nonatherothrombotic vascular disease, namely vasculitides, fibromuscular dysplasia, or dissection were excluded from the present study.

\section{Methods}

Detailed history, including history of hypertension, diabetes, TLAs, coronary artery disease, smoking, alcohol intake, and drug history was recorded in all individuals. All patients underwent CT scan/MRI of head, Doppler analysis of neck vessels, transthoracic echocardiography, detailed lipid profile along with routine biochemistry, and hemogram. Transoesophageal echocardiography was done in select group of patients of young stroke. Patients of young stroke also underwent procoagulant workup including protein $\mathrm{C}$, protein $\mathrm{S}$, antithrombin III deficiency, APLA, and vasculitic workup for RA factor, ANA, LE cell, and ANCA was performed for patients with young stroke. The patients positive for these investigations were excluded from the present study.

\section{Plasma homocysteine levels estimation}

Fasting levels were measured at least 3 months after the acute ischemic episode. Two milliliters of blood was drawn and collected in a tube containing the anticoagulant EDTA. The sample was immediately kept in ice pack and later centrifuged within $30 \mathrm{~min}$ to avoid false elevation of homocysteine levels due to its release from RBC. Plasma samples were then refrigerated and stored at $-80^{\circ} \mathrm{C}$ till the analysis was done. Total plasma homocysteine was determined by high-performance liquid chromatography (HPLC).

The assay used, measured the total homocysteine (tHcy), in both the reduced and oxidized forms. Homocysteine was dissociated from nonrelevant proteins and other disulfides by reduction with sodium borohydride $\left(\mathrm{NaBH}_{4}\right)$. The proteins were then precipitated by using $0.6 \mathrm{M}$ perchloric acid. The sulfhydryl amino acids so obtained were made to react with fluorescent reagent 7 -fluro-benzo-2-oxa-1,3 diazole-4 sulfonic acid (SBDF) (Sigma laboratories). Homocysteine was quantified by using reverse phase HPLC (Waters India Ltd., India) and fluorescence detection, as per predefined method. ${ }^{[14]}$

\section{Statistical analysis}

Descriptive values were expressed as mean \pm SD. Further analysis was done using students ' $t$ ' test and odds ratio for different variables was calculated. Chi-square test was used for testing proportion. ' $P$ ' value of $<0.05$ was considered statistically significant.

\section{Ethical consideration}

The project was approved by the local ethical committee of the institute. Venepuncture is a minimally invasive procedure used frequently as part of the investigation procedure in patients with stroke. The patients were informed about the study and the benefit thereof. After taking consent, $2 \mathrm{ml}$ of blood was withdrawn.

\section{Results}

Table 1 summarizes the clinical profile of the patients and controls in four subgroups included in the present study. Plasma tHcy levels were significantly high in all the patients with stroke when compared to controls (mean 9.91 \pm 2.25 vs $8.00 \pm 2.74 \mathrm{mmol} / \mathrm{l}$; degree of freedom, d.f. $85 ; 95 \%$ confidence interval, CI $0.72-2.99 ; P<0.001)$. The levels were significantly high in both younger age group patients $(10.85 \pm 2.38$ vs $8.32 \pm 2.89 \mathrm{mmol} / \mathrm{l}$; d.f. $37 ; 95 \%$ CI $0.92-4.14 ; P=0.003)$ and older age group patients $(9.42 \pm 1.92$ vs $7.69 \pm 2.65 \mathrm{mmol} / \mathrm{l}$; d.f. 46 ; $95 \%$ CI $0.35-$ $3.11 ; P=0.02)$. In subgroup analysis, significantly high levels were seen in male patients as compared to controls $(10.24 \pm 2.34$ vs $8.45 \pm 2.72 \mathrm{mmol} / \mathrm{l}$; d.f. $61 ; 95 \%$ CI $0.79-3.34 ; P=0.01)$ as well as in female patients compared to controls $(9.08 \pm 1.81$ vs $6.79 \pm 2.60 \mathrm{mmol} / \mathrm{l}$; d.f. 22 ; 95\% CI $0.42-3.90 ; P=0.04)$. Although the levels of tHcy were more in males as compared to females in both cases and controls in the present study but the differences were not statistically significant. No significant difference in tHcy levels 
was observed in patients suffering from large vessel disease as compared to those with small vessel disease in the present study $(10.15 \pm 2.36$ vs $9.44 \pm 1.99 \mathrm{mmol} / \mathrm{l}$; d.f. $55 ; 95 \%$ CI $0.44-2.27 ; P>0.1)$.

A positive correlation of smoking with hyperhomocysteinemia was observed in the present study as indicated by the mean tHcy levels in smokers vs nonsmokers in patient group $(11.17 \pm 1.35$ vs $9.33 \pm 2.22 \mathrm{mmol} / \mathrm{l}$; d.f. 55 ; $95 \% \mathrm{CI}$ $0.42-3.07 ; P=0.01)$, and control group (10.57 $\pm 1.3 \mathrm{vs}$ $7.36 \pm 2.65 \mathrm{mmol} / \mathrm{l}$; d.f. $28 ; 95 \%$ CI $0.89-5.49$; $P=0.008)$. Concentration of tHcy was found to be significantly high in patients with hypertension and of ischemic stroke as compared to normotensives $(10.96 \pm 2.02 \mathrm{vs}$ $9.49 \pm 2.57 \mathrm{mmol} / \mathrm{l}$; d.f. $55 ; 95 \%$ CI $0.16-2.67 ; P=0.02)$ as well as in controls $(10.68 \pm 0.89$ vs $7.59 \pm 2.7 \mathrm{mmol} / \mathrm{l}$; d.f. $28 ; 95 \%$ CI $0.25-5.91 ; P=0.03)$, further suggesting a positive correlation of hypertension with hyperhomocysteinemia in the present study. No significant correlation of tHcy levels was obtained in patients with obesity, diabetes, hyperlipidemia associated coronary artery disease, etc., due to the small sample size. After multivariate logistic regression analysis with adjustment for sex, smoking, hypertension,

\begin{tabular}{|c|c|c|c|c|}
\hline & Group I & Group II & Group III & Group IV \\
\hline Groups & $\begin{array}{l}\text { Patients } \\
<40 \text { years } \\
(n=24)\end{array}$ & $\begin{array}{c}\text { Patients } \\
>40 \text { years } \\
(n=33)\end{array}$ & $\begin{array}{l}\text { Controls } \\
<40 \text { years } \\
(n=15)\end{array}$ & $\begin{array}{c}\text { Controls } \\
>40 \text { years } \\
(n=15)\end{array}$ \\
\hline Mean age (years) & 28.54 & 54.52 & 30.60 & 52.53 \\
\hline Males (\%) & 75.0 & 69.7 & 66.0 & 80.0 \\
\hline Smokers (\%) & 25 & 36.4 & 13.3 & 13.3 \\
\hline Hypertensives (\%) & 16.7 & 66.7 & 13.3 & 13.3 \\
\hline Diabetics (\%) & 0 & 15.5 & 0 & 0 \\
\hline Obese (\%) & 8.3 & 30.3 & 13.3 & 20.0 \\
\hline Mean $\pm \mathrm{SD}(\mu \mathrm{mol} / \mathrm{l})$ & $10.85 \pm 2.38$ & $9.42 \pm 1.92$ & $8.32 \pm 3.89$ & $7.69 \pm 2.65$ \\
\hline Range of $\mathrm{tHcy}(\mu \mathrm{mol} / \mathrm{l})$ & $6.07-15.56$ & $6.27-13.62$ & $2.29-11.67$ & $4.38-11.44$ \\
\hline
\end{tabular}

\begin{tabular}{|c|c|c|c|c|}
\hline & \multicolumn{2}{|c|}{ Stroke patients } & \multicolumn{2}{|c|}{ Controls } \\
\hline Sub groups & $\begin{array}{c}\text { Number } \\
(\text { tHcy })^{\star}\end{array}$ & Mean $(\mu \mathrm{mol} / \mathrm{l})$ & $\begin{array}{c}\text { Number } \\
(\text { tHcy })^{\star}\end{array}$ & Mean $(\mu \mathrm{mol} / \mathrm{l})$ \\
\hline Males & 41 & $10.24 \pm 2.34$ & 22 & $8.45 \pm 2.72$ \\
\hline Females & 16 & $9.08 \pm 1.81$ & 8 & $6.79 \pm 2.60$ \\
\hline Smokers & 18 & $11.17 \pm 1.35$ & 6 & $10.57 \pm 1.30$ \\
\hline Nonsmokers & 39 & $9.33 \pm 2.62$ & 24 & $7.36 \pm 2.65$ \\
\hline Hypertensives & 25 & $10.96 \pm 2.02$ & 4 & $10.68 \pm 0.89$ \\
\hline Nonhypertensives & 32 & $9.49 \pm 2.57$ & 26 & $7.59 \pm 2.70$ \\
\hline
\end{tabular}

*tHcy, total homocysteine levels.

Table 3: Showing odd's ratio and confidence intervals of different variables in present study

\begin{tabular}{lcc}
\hline Variables & Odd's ratio & Confidence interval \\
Male sex & 0.93 & $0.34-2.52$ \\
Smoking & 1.85 & $0.64-5.30$ \\
Hypertension & 5.08 & $1.57-16.45$ \\
Obesity & 0.83 & $0.42-4.22$ \\
tHcy levels & 1.56 & $0.62-3.93$ \\
\hline
\end{tabular}

obesity and homocysteine levels [Table 2], hypertension $(P$ $<0.03)$, and hyperhomocysteinemia $(P<0.01)$ emerged as significant risk factors in the present study [Table 3].

\section{Discussion}

In this case-control study, we found a strong correlation of hyperhomocysteinemia with ischemic stroke in both younger and older age group. The results of the present study are consistent with many case-control and prospective studies ${ }^{[6]-[11]}$ involving patients of all age groups, although few prospective studies have failed to establish any association between hyperhomocysteinemia and stroke [Table 4]. ${ }^{[12],[13]}$ There is no definite threshold level for homocysteine that correlates with a sudden increase in the risk of vascular events. Indeed, the relation between tHcy and ASVD appears to be linear or ( $\log$ linear), in much the same way as increasing blood pressure and cholesterol are related to the development of vascular disease. ${ }^{[15]}$ Although the normal range for homocysteine level has been proposed to lie between 5 and $15 \mu \mathrm{mol} / \mathrm{l},{ }^{[15]}$ a large number of studies have documented increased risk of vascular disease within this range as in our study also [Table 4].

Hyperhomocysteinemia has a multifactorial origin incorporating genetic, nutritional, pharmacological, and pathological factors. Considering the differences in dietary, genetic, and ethnic factors, the data published from the West may not be applicable to our population. Because our observations are based on a small group of patients and control population, it is difficult to propose a definite cut off value for homocysteine levels to be taken as significant and would require a larger population analysis.

No significant difference in the mean homocysteine levels were seen in patients with large vessel disease (thromboembolic strokes) compared to small vessel disease (lacunar strokes). Similar observations were made by Lindgren et al., ${ }^{[16]}$ who could not find any independent correlation between plasma homocysteine concentration and the infarct subtype (cortical vs lacunar), or to the degree of carotid artery stenosis. However, in one large study by Eikelboom et al., ${ }^{[9]}$ the association was far higher in the patients with large artery disease as compared to those with small artery disease. They proposed that the deleterious effect of hyperhomocysteinemia is medi-

Table 4: Prospective Cohort and case-control studies of homocysteine and stroke

\section{Study}

Graham et al. ${ }^{[6]}$

Meiklejohn et al. ${ }^{[7]}$

Giles et al. ${ }^{[8]}$

Eikelboom et al. ${ }^{[9]}$

Fallon et al. ${ }^{[10]}$

Perry et al. ${ }^{[11]}$

Verhoef et al..$^{[12]}$

Alfthan et al. ${ }^{[13]}$

Present study

\section{Total homocysteine ( $\mu \mathrm{mol} / \mathrm{l})$}

Cases

11.11

10.1

11.9

12.4

13.3

13.7

11.1

10.1

9.91

\section{Controls}

9.73

8.2

10.2

10.5

12.6

11.9

10.6

9.3 8.00

\section{$P$ value}

$\mathrm{S}$

$S$

$S$

$\mathrm{S}$

$S$

$S$

NS

NS

$S$ 
ated primarily via a proatherogenic effect and less likely due to prothrombotic effect, which might be contributory in the large vessel disease. Contrary to the above observations, Evers et al. ${ }^{[17]}$ found that elevated homocysteine levels were associated with cerebral microangiopathy and not with cardioembolic or macroangiopathy-associated ischemic stroke. There is evidence that hyperhomocysteinemia is both atherogenic and prothrombotic, operating through a variety of potential mechanisms including direct endothelial injury, mitogenic effect on smooth muscle cells, impaired endogenous fibrinolysis, endothelial nitrous oxide response, and alteration in arachnoidic acid metabolism. ${ }^{[3],[4],[17]}$

This study found significantly high levels of homocysteine in smokers as compared to nonsmokers in patients with stroke, as well as in controls. Many authors ${ }^{[6],[18],[19]}$ have also observed that cigarette smoking was positively associated with highhomocysteine concentration. In the Hordaland homocysteine study, Nygard et al. ${ }^{[19]}$ observed that compared to nonsmokers, smokers had a distinctly higher plasma tHcy levels that increased almost linearly with the number of cigarettes smoked daily. They proposed that smoking is accompanied by changes in plasma thiol-redox state due to higher formation of reactive oxygen species. Furthermore, reduced intake of nutrients and vitamins were also contributing to the increased homocysteine levels in heavy smokers. ${ }^{[19]}$ However, a negative correlation was observed by Perry et al. ${ }^{[11]}$ Additional studies are needed to examine whether smoking cessation can reduce homocysteine concentrations.

Homocysteine levels were significantly higher in patients with hypertension and stroke of either age group as compared to normotensives in the present study. Strong association between hypertension and tHcy level in stroke patients had also been observed by other authors. ${ }^{[6],[11],[20]}$ It is proposed that hyperhomocysteinemia induces an elastolytic process in the arterial wall, by inducing synthesis and secretion of serine elastase. The loss of elastin may lead to the stiffening of the arterial wall resulting in hypertension. This might be one of the factors, by which hyperhomocysteinemia contributes as a risk factor for stroke, although other concomitant factors may also exist. ${ }^{[3],[4]}$

The present study has some limitations. Because of the smaller number of cases and controls in the present study group, exact significance of high-tHcy levels in many subgroups of patients could not be established. Moreover, a larger number of normal persons need to be screened to find out the normal levels of tHcy in the general population in the Indian subcontinent. Also, we could not measure the $\mathrm{B}_{12}$ and folate levels in our study group, which are co-factors in homocysteine metabolism and have been documented to be strong correlates of tHcy in many studies. Another important limitation is the fact that in a case-control design, homocysteine levels are measured after the stroke. So, it cannot be determined whether elevation in homocysteine was a precursor, or a consequence of stroke. The crucial question still remains whether plasma
tHcy is directly involved in the pathogenesis of vascular disease or just a marker for increased risk. Intervention studies in animals and human are needed to determine which of the potential mechanisms of homocysteine-associated vascular risk factors are modifiable by targeted vitamin therapy. Recently initiated primary and secondary prevention trials will determine whether lowering of homocysteine levels with vitamin B interventions will lower vascular disease events.

\section{Conclusions}

Increased homocysteine level is an important risk factor for the development of ischemic stroke in all populations especially in younger age group. Hypertension and smoking per se are important contributory factors for hyperhomocysteinemia. Absolute values of high-homocysteine levels cannot be established on the basis of this study. A larger normal Indian population needs to be screened to establish a definite 'high' level of homocysteine. It will be worthwhile to consider homocysteine levels of above $10 \mu \mathrm{mol} / \mathrm{l}$ as significant in patients with stroke for secondary prevention and supplementation with folate and vitamin B.

\section{References}

1. 2000 Heart and Stroke Statistical Update. Dallas. American Heart Association, 2000.

2. Whisnat JP. Modeling of risk factors for ischemic stroke: the Willis lecture Stroke 1997;28:1839-43.

3. Stein JH, McBride PE. Hyperhomocysteinemia and atherosclerotic vascular disease. Pathophysiology, screening and treatment. Arch Intern Med 1998;158:1301-06.

4. Arrastia RD. Homocysteine and neurologic disease. Arch Neurol 2000;57:1422 26.

5. Me Kully KS. Vascular pathology of homocysteinemia: implications for the pathogenesis of atherosclerosis. Am J Pathol 1969;56:111-28.

6. Graham IM, Daly LE, Refsum HM, Robinson K, Brattstrom LE, Ueland PM. Plasma homocysteine as a risk factor for vascular disease. The European Concerted Action Project. JAMA 1997;277:1775-81.

7. Meiklejohn DJ, Vickers MA, Dijkhuisen R, Greaves M. Plasma homocysteine concentrations in the acute and convalescent periods of atherothrombotic stroke. Stroke 2001;32:57-62

8. Giles WH, Croft JB, Greenland K.J, Ford ES, Kittner SJ. Total homocysteine concentration and the likelihood of nonfatal stroke. Results from the Third National Health and Nutrition Examination survey (1988-1994). Stroke $1998 ; 29: 2473-77$

9. Eikelboom JW, Hankey GJ, Anand SS, Lofthouse E, Staples N, Baker RI. Association between high homocysteine and ischemic stroke due to large and small artery disease but not other etiologic subtypes of ischemic stroke. Stroke 2000;31:1069-75.

10. Fallon UB, Virtamo J, Young I, MeMaster D, Ben-Shlomo Y, Wood N, Whitehead AS, Smith GD. Homocysteine and cerebral infarction in finnish male smokers. Stroke 2003;34:1359-63.

11. Perry IJ, Refsum H, Morris RW, Ebrahim SB, Ueland PM, Shaper AG. Prospective study of serum total homocysteine concentration and risk of stroke in middle aged British men. Lancet 1995;346:1395-98.

12. Verhoef P, Hennekens CH, Malinow MR, Kok FJ, Willet WC, Stampfer MJ. A prospective study of plasma homocysteine and risk of ischemic stroke. Stroke $1994 ; 25: 1924-30$

13. Alfthan G, Pekkanen J, Jauhiainen M, Pitkaniemi J, Karvonen M, Tuomilehto J, et al. Relation of serum homocysteine and lipoprotein (a) concentrations to atherosclerotic disease in a prospective Finnish population based study. Atherosclerosis $1994 ; 106: 9-19$.

14. Fiskerstrand T, Refsum H, Kvalheim G, Ueland PM. Homocysteine and other thiols in plasma and urine: Automated determination and sample stability. Clin Chem 1993;39:263-71.

15. Hankey GJ, Eikelboom JW. Homocysteine and vascular disease. Indian Heart J 2000;52:18-26. 
16. Lindgren A, Brattstrom L, Norrving B, Hultberg B, Anderson A. Plasma homocysteine in acute and convalescent phases after stroke. Stroke 1995;26:795800 .

17. Evers S, Koch HG, Grotemever KH, et al. Features, symptoms and neurophysiological findings in stroke associated with hyperhomocysteinemia. Arch Neurol 1997;54:1276-82

18. Malinow MR. Hyperhomocysteinemia: A common and easily reversible risk factor for occlusive atherosclerosis. Circulation 1990;81:2004-06.
19. Nygard O, Vollser SE, Refsum H, et al. Total plasma homocysteine and cardiovascular risk profile. The Hordaland Homocysteine study. JAMA 1995;274:1526-33.

20. Araki A, Sako Y, Fushima Y, Asada T, Kim T. Plasma sulfhydryl contained amino acid in patients with cerebral infaretion and in hypertensive subjects. Atherosclerosis 1989;79:1139-45.

Accepted on 3-6-2005

\section{Invited Comments}

For over 30 years, there has been a belief that hyperhomocysteinemia plays a role in atherothrombosis. ${ }^{[1]}$ However, not until recently has epidemiological evidence (over 100 case-control, cross-sectional, and prospective studies) shown an association between homocysteine levels and vascular disease. ${ }^{[2]}$ Regarding stroke risk, the evidence is still emerging. Trends for an association of the highest quartile of homocysteine and stroke have been seen in the Framingham Study as well as British Regional Heart Study. ${ }^{[3],[4]}$ In the Northern Manhattan Study, elevation greater than $15 \mathrm{mg} / \mathrm{dl}$ was associated strongly with vascular death, combined vascular outcomes, and with ischemic stroke in a tri-ethnic population. The link between moderate homocysteine elevations (10-15 $\mathrm{mol} / \mathrm{l}$ ) and ischemic stroke were less dramatic than for vascular death and combined vascular events. ${ }^{[5]}$ The Homocysteine Collaborative Group's meta-analysis of the data concluded that a moderate independent association existed with a $25 \%$ lower level being associated with about a $10 \%$ lower stroke and cardiac risk in asymptomatic persons. ${ }^{[6]}$ The study in the current issue of Neurology India corroborates this association in Indian patients with stroke. ${ }^{[7]}$

While there seems to be a strong association and perhaps a dose-dependent relationship between homocysteine and vascular disease, the leap from association to causality has been difficult. Evidence from genetic conditions known to elevate homocysteine 10-50 times than the general population (i.e. cystathionine B-synthase), would support the hypothesis that early atherosclerosis is linked to elevated homocysteine levels. However, genetic studies have also failed to show an association with vascular disease in those with some genotypes known to cause hyperhomocysteinemia. ${ }^{[8]}$ In addition, biologic plausibility is still largely speculative despite emerging evidence that suggests it may cause endothelial damage via oxidative stress mechanisms, alterations of coagulation properties, and impairment of vasomotor regulation. ${ }^{[9]}$ These, however, have been studies in which concentrations of homocysteine are 10 times greater than seen in most patients with moderately elevated levels.

Furthermore, to satisfy Bradford Hill's criteria for epidemiologic causality, homocysteine may need to pass one last hurdle: removing the exposure or treating it should decrease the risk of the disease. Therefore, treatment for hyperhomocysteinemia with multivitamins (folate, $\mathrm{B}_{12}$, and $\mathrm{B}_{6}$ ), which has been shown to reduce homocysteine levels even in individuals not vitamin deficient, ${ }^{[10]}$ should lower the risk of vascular outcomes. Multivitamin therapy has been demonstrated to reduce homocysteine levels and cardiovascular risks among those with genetic causes of marked hyperhomocysteinemia. ${ }^{[11]}$ Surrogate markers such as carotid plaque likewise show regression with homocysteine-lowering therapy. ${ }^{[12]}$ However, in a recent large international randomized trial among stroke survivors with moderate homocysteinemia, multivitamin therapy showed no reduction in the risk of stroke recurrence. ${ }^{[13]}$ Ongoing trials such as VITATOPS may help address the question regarding the benefits of homocysteinelowering therapies. ${ }^{[14]}$

For now, the preponderance of evidence from many epidemiologic, basic scientific, and genetic studies suggests that homocysteine is moderately associated with cardiovascular disease (stroke included). Given the safety and low cost of multivitamin therapy, recommendations suggest starting $\mathrm{B}_{12}$, folate, and $\mathrm{B}_{6}$ in those with elevated homocysteine and cardiovascular disease. ${ }^{[15]}$ Whether reducing homocysteine will translate into a reduction in vascular or stroke risk is still an area of uncertainty.

\section{S. Prabhakaran, Ralph Sacco}

The Neurological Institute, Columbia University, Stroke and Critical Care Division, 710 W 168th Street, Room 640, New York, NY10032, USA E-mail: SPrabhakaran@neuro.columbia.edu

\section{References}

1. MeCully KSVascular pathology of homocysteinemia: implications for the pathogenesis of arteriosclerosis. Am J Pathol 1969;56:111-28,

2. Bots ML, Launer L.J, Lindemans J, et al. Homocysteine, atherosclerosis, and prevalent cardiovascular disease in the elderly: the Rotterdam study. J Intern Med 1997;242:339-47

3. Bostom AG, Rosenberg IH, Sibershatz H, et al. Nonfasting plasma homocysteine levels and stroke incidence in elderly persons: the Framingham Study. Ann Intern Med 1999;131:352-55.

4. Pery IJ, Refsum H, Morris RW, et al. Prospective study of serum total homo- 
cysteine concentration and risk of stroke in middle aged British men. Lancet $1995 ; 346: 1395-98$

5. Sacco RL, Anand K, Lee HS, et al. Homocysteine and the risk of ischemic stroke in a triethnic cohort. The Northern Manhattan Study. Stroke 2004;35:2263-69

6. Homocysteine Studies Collaboration and risk of ischemic heart disease and stroke: a meta-analysis. JAMA 2002;288:2015-22.

7. Modi M, Prabhakar S, Majumdar1 S, Khullar1 M, Lal V, Das CP Hyperhomocysteinemia as a risk factor for ischemic stroke: An Indian scenario. Neurol India 2005;53:297-302

8. Frosst P, Blom H.J, Milos R, et al. A candidate genetic risk factor for vascular disease: a common mutation in methylenetetrahydrofolate reductase. Nat Genet 1995;10:111-3.

9. Welch GN, Upchurch G, Jr. Loscalzo J, Hyperhomocyst(e)inemia and atherothrombosis. Ann N Y Acad Sci 1997;881:48-58.

10. Homocysteine Lowering Trialists' Collaboration. Lowering blood homocysteine with folic acid based supplements: meta-analysis of randomized trials. BMJ
1998;316:894-98.

11. Wilcken DEL, Wilcken B. The natural history of vascular disease in homocystinuria and the effects of treatment. J Inher Metab Dis 1997;20:295 300 .

12. Peterson JC, Spence JD. Vitamins and progression of atherosclerosis in hyperhomocyst(e)inaemia. Lancet 1998;351:263.

13. Toole JF, Malinow MR, Chambless LE, et al. Lowering homocysteine in patients with ischemic stroke to prevent recurrent stroke, myocardial infarction and death: the Vitamin Intervention for Stroke Prevention (VISP) randomized controlled trial. .JAMA 2004;291:565-75.

14. The VITATOPS Trial Study Group. The VITATOPS (Vitamins to Prevent Stroke) Trial: Rationale and design of an international, large, simple, randomised trial of homocysteine-lowering multivitamin therapy in patients with recent transient ischemic attack or stroke. Cerebrovase Dis 2002;13:120-6.

15. Goldstein LB, Adams R, Becker K, et al. Primary prevention of ischemic stroke: A statement for healtheare professionals from the Stroke Council of the American Heart Association. Circulation 2001;103:163-82.

\section{Invited Comments}

This study shows that hyperhomocysteinaemia is associated with an increased risk of stroke in India as has been shown in many other countries in the world. Elevated homocysteine is a risk factor for stroke both in the young ${ }^{[1]}$ and in the elderly, ${ }^{[2]}$ as well as for recurrent stroke. ${ }^{[3]}$ Numerous studies have shown that supplementation with folate, vitamin B6, and B12 reduces the level of homocysteine. Intervention studies have so far been disappointing in being unable to show a reduced risk of stroke and cardiovascular events in vitamin B-treated groups, ${ }^{[4,5]}$ however, the results of many ongoing randomized trials are awaited with great expectations. ${ }^{[6]}$ In the meantime, however, it is tempting to recommend vitamin supplementation for patients with highly elevated homocysteine levels.

Gudrun Boysen, Dept. of Neurology, Bispebjerg Hospital, DK-2400 Copenhagen NV, E-mail: gb01@bbh.hosp.dk

\section{References}

1. Bos MJ, van Goor ML, Koudstaal PJ, Dippel DW. Plasma homocysteine is a risk factor for recurrent vascular events in young patients with an ischemic stroke or TIA. J Neurol 2005;152:332-7.

2. Iso H, Moriyama Y, Sato S, Kitamura A, Tanigawa T, Yamagishi K, et al Serum total homocysteine concentrations and risk of stroke and its subtypes in Japanese. Circulation 2004;109:2766-72.

3. Boysen G, Brander T, Christensen H, Gideon R, Truelsen T. Homocysteine and risk of recurrent stroke. Stroke 2003;34:1258-61.

4. Toole JE, Malinow MR, Chambless LE, Spence JD, Howard VJ, Sides EG, et al. Lowering homocysteine in patients with ischemic stroke to prevent recurrent stroke, myocardial infarction, and death. JAMA 2004;291:565-75.

5. Lange H, Suryapranata H, De Luca G, Borner C, Dille J, Kallmayer K, et al. Folate therapy and in-stent restenosis after coronary stenting. N Engl J Med 2004;350:2673-81

6. Clarke R. Homocysteine-lowering trials for prevention of heart disease and stroke. Semin Vasc Med 2005;5:215-22. 